the fact of the immediate and progressive improvement without it, it was not later enforced.

September 1, 1886, Dr. Lord wrote me, " our patient is improving steadily every day. The motion in the abdomen is hardly felt. The pulse has fallen to a hundred. His appetite is reasonably good and nothing which he eats seems to hurt him. He has rested well nights, and in fact has been comparatively comfortable. He is gaining some flesh." Under date of January 27,1887 , he wrote again as follows: "after two months of rest in bed, he began to sit up a little, and gradually resumed moderate exercise by walking. About the middle of November he began to ride out. I think he has gained twenty-five pounds of flesh. He has taken the iodide of potassium all the time with occasional omissions of a day or two. He says he feels so much better while taking it he is unwilling to leave it off." Later reports were in the same strain.

On the 10th of May, 1887, I saw him again at Cumberland Mills, to which village he had returned. His wife said he had been so much better, and was feeling so down-hearted at being so long idle, he had commenced the day before to do a little light work at the mills. His work consisted in watching the paper as it moved by him at a given point, and removing any soiled sheets. There was no lifting or other heavy work, and sometimes there would be nothing to do for twenty minutes at a time. I was waiting at his house for him when he came home to dinuer. His wife was with him and he had been walking perhaps the sixteenth of a mile. He was slightly out of breath with the effort of walking. and remarked that the mere announcement that I had come out to see him, though he was glad to see me, had made his heart palpitate. His weight was a hundred and fifty-one pounds; pulse a hundred, even, and fairly strong; tongue clean and appetite good. He was somewhat anæmic, his nerves were easily disturbed, he was slightly dyspnœic on moderate effort, and palpitation was easily induced, but he had greatly improved since $\mathrm{my}$ first visit to him.

He gave the following account of himself. After my visit of August 1st, he had staid in bed for two months. In about three days after beginning the treatment the thirst and burning at the epigastrium suddenly left him. In October, when he began to get up, the heating and palpitation were greatly reduced. Since then they had largely subsided till now most of the time he does not notice them at all. $\mathrm{He}$ said that he was entirely free from them for weeks in the early winter, till in January he was thrown from a sleigh, after which he suffered more or less from them for several weeks. Exertion, excitement, or worry brings them on slightly. They have from the first been worse on waking in the morning, and he has been most free from them in the evening. Even within a few days, while considering the question of resuming work, he has had to sit up in bed, on waking, with heart-beating. The throbbing and tenderness, which he used to feel at the site of the aneurism, are only rarely and slightly felt now. Sometimes these sensations seem to him as if moved a little higher up, but his fingers recognize the aneurismal mass in the old spot. When he began to get up after his bed-rest, he could not at first bend directly forward to pick up anything from the floor, but had to get at it sideways. Now he can pick anything up naturally. He says he little thought at one time he should ever be as well as he now is. He called my attention to two swellings at the base of the neck one on each side, just above the clavicles and near their sternal ends. His wife said if he gets cold and coughs hard, they swell to be as large as halfhen's eggs. They appear like sacular dilatations of the jugular veins.

On examination anteriorly, the aneurismal mass was found in sitû, and not increased in size, while both impulse and expansion were diminished, and the blowing sound was but faintly recognizable through the stethescope. On examination posteriorly, the independent centre of pulsation and double sound was found as before, but both motion and sound were greatly reduced in amount, and the "booming" quality of the sound was gone.

My conclusion as to the present condition is that a partial cure of the aneurism has been effected, the sac having been in large measure filled up with concentric layers of fibrine; also, that an inflammation which probably involved the walls of the aorta higher up than the level of the aneurism, has been largely or wholly reduced. The condition of the patient is therefore immensely improved.

My estimate of the chances of final and permanent recovery is not very hopeful. If the pecuniary circumstances of the patient were more favorable to rest of body and tranquility of mind; if he could live without either working or worrying about the support of himself and his family; and if he could have such recreation and change of scene as he might fancy, the prospect would be improved. But with all such conditions at the best, I should still make a very guarded prognosis. There are too many unfavorable liabilities. Embolism may easily occur; or suppurative inflammation may arise in the walls of the sac inducing pyæmia; or atheromatous degeneration may supervene, invading the aortic coats higher up which have already been the seat of inflammation; or in some other way, more or less direct, the aneurism may yet prove fatal.

\section{WAS IT BERI-BERI?}

\section{BY G. B. STEVENS, M.D., GLOUCESTER.}

ON May 13th, I visited at his home in this city the mate of the barque Charles G. Rice, which arrived in Boston the day previous from Manilla after a passage of one hundred and twenty days. He was perfectly well when he left the latter port; when about one month out he was taken with diarrhœa, having daily " nine to sixteen discharges of blood and slime." Great thirst began at this time, and continued for the rest of the passage. He drank very largely of the water caught from the ship's houses after rains, and polluted by "chicken dung and tobacco juice." After the diarrhœa had lasted for two months, he began to "feel tired in the calves of the legs"; three or four days. later, that is, one month before arrival in Boston, he noticed, while sitting on the rail with his legs hanging, that the right leg below the knee was swollen. The left leg began to swell a few days later. One week before arriving in Boston the penis became œedematous. The cedema of the scrotum, which appeared three or four days later, would nearly disappear during each night. The diarrhwa had lasted up to this time, though during the latter part of the voyage the discharges averaged but two to four a day. This, be 
thinks, may have been due to the better quality of the up. The broom-top was omitted. On the 23d, the water, as they then used in part that stored in the œedema was all gone. The appetite was more natural; butts. He never had any vomiting, but a disrelish for thirst was less. The bowels were moving but twice or food, almost amounting to loathing. They had a thrice daily; the discharges contained little blood. plenty of fresh poultry, and canned food carried from After the odema had gone he complained of numbness the States a year and a half before. He did full duty in the legs, most marked below the knee, especially in until the last four days, and during that time did not the calves of the legs. Pinching or scratching the give up entirely.

I saw the patient an hour or two after his arrival in this city. He was sitting up; through breathing his native air, perhaps, the anorexia of the sea-voyage had given place to a craving for food, and already preparations were making for the first meal in his old home to be of Gloucester's great food-product. $\mathrm{He}$ told me he had the "dropsical scurvy." This, he said, was the opinion of the captain, who had suffered similarly on a previous voyage, and at an English hospital this name had been given to the disorder. Looking for scurvy, I found no bleeding or sponginess of the gums, no ecchymoses in the cutaneous surface, no history of hæmorrhages excepting with the intestinal discharges. The dropsy, however, was evident enough. It was most noticeable below the trunk. The genitals were enormously swollen. The feet and legs were œdematous, pitting slightly on pressure. The left thigh was less swollen than the right. There was cedema over the pubes. The backs of the hands and wrists were somewhat puffy. The face appeared to be slightly swollen symmetrically, but there was no puffiness about the lids. I found no evidence of ascites, of pericardial or pleural effusion. The appearance of the face was that of plethora, and not of anæmia. The pulse was between 90 and 100 , and somewhat irregular. The tongue was clean and moist. The bowels were acting four or five times daily, and the impulse to relieve them came very suddenly, and had to be quickly responded to, or the discharge would be beyond control. The urine was scanty. Thirst was extreme, and the appetite had become great. $\mathrm{He}$ said he was "well all but the swelling," which was very inconvenient.

He was ordered to bed, allowed to satisfy his appetite at first, but told that it would soon be restricted.

On the day following he was put on a diet of milk porridge with bread, and ordered three times a day fifteen minims of tr. digitalis with potass. acet. and gin. Dover's powder was prescribed for the diarrhœa. The next day, the $15 \mathrm{th}$, a specimen of the urine was examined: the color was dark ; the reaction, strongly acid; the specific gravity, 1,015; no albumen was found. On the $17 \mathrm{th}$, diuresis had begun, but was not continuous. A specimen of the urine examined was pale, acid in reaction, of the specific gravity of 1,014. No albumen was found, nor anything abnormal under the microscope. Half an ounce of the infusion of digitalis three times a day, and an infusion of broom-top were substituted for the diuretic mixture first ordered. The porridge, he thought, caused a feeling of fulness at the stomach, it was accordingly omitted, and milk, eggs, and bread allowed night and morning, with fish and bread at noon. The appetite was still very large; thirst was great. The discharges from the bowels were thin and somewhat bloody, but were less in number. On the $20 \mathrm{th}$, the kidneys were acting with great energy, principally during the nighttime. 'The œdema everywhere was much lessened. Pulse 72, full and regular. On the 21 st, the œdema was to be seen only in the prepuce. The patient was sitting skin in this situation produced but little sensation. He never seemed to have noticed this on ship-board, and it certainly was not a symptom in the early part of the time he was under my care. On the $26 \mathrm{th}$, the kidneys were acting freely, but not immoderately. Their secretion showed nothing abnormal. 'The digitalis was omitted, and fifteen minims of the tincture of the chloride of iron were ordered three times a day. The appetite was quite natural, and a more varied diet was allowed. The bowels were moving twice daily without blood. The patient walked out for the first time on this date, and was discharged.

The lax condition of the skin, even where the œdema had not been great, as, for example, about the hands and face, was very noticeable. A shrinkage, from a partial desiccation of the tissues through the large amount of water eliminated by the kidneys, seemed to have resulted. The patient said he had never been so thin. A pair of trousers, that fitted him four months before, were distended to their utmost when he reached home, and two weeks later they were loose almost to a ludicrous degree. He complained much of numbness of the legs. This seemed to have increased.

The case is not reported as positively one of beriberi, but I think there is reason to believe it may have been. The dropsy was certainly of an uncommon form, and, in my opinion, was not traceable to the usual causes. On the other hand, the condition of the bowels was unlike that met with in most of the cases of beri-beri that I have read of; constipation has seemed to be the rule. The nervous symptoms, consisting only of impaired sensation in the lower extremities, were a late occurrence.

\section{Elinital $\mathfrak{\text { Agmarandum. }}$}

\section{A CASE OF TOXIC SYMPTOMS ARISING FROM THE USE OF COCAINE.}

BY EDWIN W. BULLOCK, M.D., HAVERHLL, MASS.

During the last few months I have used cocaine quite freely, especially for producing anasthesia of mucous surfaces. Therefore, the following case of toxic effect from the drug after giving me considerable anxiety for the time being, has seemed to be sufficiently interesting and instructive to warrant my reporting it to the JocrnaL.

Sunday, May 15th, Mr. P., aged 24, came to my office to have tonsillitomy performed. In order to obtain anæsthesia, I employed first, a spray of a four per cent. solution of cocaine (Squibb's four per cent. solution with boric acid being the one used), then, by means of a sub-cutaneous syringe, made six injections of the same solution into the tonsils, at three different points in each.

About two drachms were used in the spray, and forty (40) minims was the whole amount injected. The operation was entirely successful, perfect anæsthesia being obtained and but very little blood lost. At 3 P. M., about four hours after the patient had left my 